\title{
Study on Impedance Characteristics of Aircraft Cables
}

\author{
Weilin Li, ${ }^{1,2}$ Wenjie Liu, ${ }^{1}$ Xiaobin Zhang, ${ }^{1}$ Zhaohui Gao, ${ }^{1}$ Meng Xie, ${ }^{1}$ and Hongxia Wang ${ }^{3}$ \\ ${ }^{1}$ Department of Electrical Engineering, Northwestern Polytechnical University, Xian 710072, China \\ ${ }^{2}$ State Key Laboratory of Electrical Insulation and Power Equipment, Xian Jiaotong University, Xian 710049, China \\ ${ }^{3}$ China Aero-Polytechnology Establishment, Beijing 100028, China
}

Correspondence should be addressed to Weilin Li; liweilin907@126.com

Received 28 July 2015; Accepted 10 March 2016

Academic Editor: Christopher J. Damaren

Copyright (C) 2016 Weilin Li et al. This is an open access article distributed under the Creative Commons Attribution License, which permits unrestricted use, distribution, and reproduction in any medium, provided the original work is properly cited.

\begin{abstract}
Voltage decrease and power loss in distribution lines of aircraft electric power system are harmful to the normal operation of electrical equipment and may even threaten the safety of aircraft. This study investigates how the gap distance (the distance between aircraft cables and aircraft skin) and voltage frequency (variable frequency power supply will be adopted for next generation aircraft) will affect the impedance of aircraft cables. To be more precise, the forming mechanism of cable resistance and inductance is illustrated in detail and their changing trends with frequency and gap distance are analyzed with the help of electromagnetic theoretical analysis. An aircraft cable simulation model is built with Maxwell 2D and the simulation results are consistent with the conclusions drawn from the theoretical analysis. The changing trends of the four core parameters of interest are analyzed: resistance, inductance, reactance, and impedance. The research results can be used as reference for the applications in Variable Speed Variable Frequency (VSVF) aircraft electric power system.
\end{abstract}

\section{Introduction}

VSVF (Variable Speed Variable Frequency) system is now under consideration for modern aircraft electric power system in order to replace CSCF (Constant Speed Constant Frequency) system, due to the fact that it is simpler and more energy-efficient and has higher power density [1]. However, the use of VSVF system also proposes new challenges, such as the voltage decrease and power loss caused by aircraft cable impedance.

An aircraft cable can be represented with series connected resistor and inductor when alternating current flows through it. The cable's resistance and inductance will not keep constant but vary due to various factors, among which the gap distance and the voltage frequency matter the most.

Nowadays in China, data of aircraft cable impedance and current-carrying capacity used is still determined by HB5795-82 released in 1982 [2]. However, the data obtained at $400 \mathrm{~Hz}$ at that time is not so accurate due to the poor equipment and backward measurement method. Moreover, this industrial standard needs to be expanded as the voltage frequency in VSVF system is variable.
Literatures can be found, which analyze or calculate the resistance and inductance of a straight conductor. References $[3,4]$ present calculation of total inductance of a straight conductor with direct current (DC) using the Biot-Savart law. Reference [5] proposes a method to calculate the AC resistance of a straight cable but the inductance is neglected. Experimental study of skin effect which is closely related to voltage frequency is displayed in [6]. The experimental result correctly reflects the change trend of cable resistance and inductance with frequency variation but it lacks theoretical analysis. In a nutshell, problems still exist in the following aspects.

(1) Most papers calculate cable resistance and inductance only concerning the condition when DC flows through the conductor $[3,4]$. Other articles study this issue under AC condition, but the conclusion is not satisfactory.

(2) Reference [7] analyzes this problem using a finite element magnetic field analysis program but does not solve the issues completely. In addition, it is necessary to popularize the method with which problems can be 
studied by building simulation models because it is more convenient to change parameters and view the current density and flux density which are not easy to achieve in practical experiments.

(3) None of the references above studies how the external electromagnetic environment will influence the resistance and inductance of transmission lines. For example, the aircraft skin has great impact on aircraft cable impedance. More attention should be paid in this area.

Thus, it becomes necessary to further study the impedance characteristic of aircraft cables.

Great efforts have been done in this paper. The impedance characteristic of an aircraft cable, when AC flows through it, consists of four relations: resistance versus frequency, inductance versus frequency, resistance versus gap distance (the distance between aircraft cables and aircraft skin), and inductance versus gap distance. Change trends of cable resistance and inductance with frequency and gap distance are analyzed based on electromagnetic theory. Some derivations based on fundamental theory are used. An aircraft cable simulation model is built using Maxwell 2D, a product of ANSYS Corporation. Simulation results are provided in both electromagnetic field graphs and data reports. Consistent conclusions are drawn from the two analytical approaches above. In this study, the voltage frequency varies within the range of $360 \mathrm{~Hz}$ to $800 \mathrm{~Hz}$. According to HB5795-82, the gap distance ranges from $r_{0}$ (the cable's radius) to $110 \mathrm{~mm}$. The gap distance is measured from the center of the cable to the surface of the aircraft skin, which means the cable clings to the aircraft skin when the gap distance equals the cable's radius $r_{0}$.

\section{Analysis Based on Electromagnetic Theory}

2.1. Resistance Analysis. It is well known that a cable's AC resistance is larger than its DC resistance. This is due to three reasons: skin effect, proximity effect, and external electromagnetic environment [8]. Proximity effect is a phenomenon that a conductor carrying a high-frequency current induces copper loss in an adjacent conductor [9]. This means at least two wires are required when referring to proximity effect. As to single cable studied in this paper, proximity effect does not exist.

Skin effect is the phenomenon that AC tends to flow mainly at the surface of a conductor which is different from distributing uniformly throughout the cross section of the conductor in the case of DC, as shown in Figure 1. Higher frequency will lead to smaller skin depth. The skin effect will reduce the effective cross-sectional area of the cables and increase the resistance [10]. It should be noted that the AC current density at the center of the cable may not necessarily be zero. In fact, the current density at the surface of the cable is only a little larger than that at the center since voltage frequency used in VSVF system is only several hundred hertz.

The AC flowing through a cable induces magnetic field which generates eddy current in aircraft skin and the eddy current causes power losses. According to the law of conservation of energy, these losses must come from the power

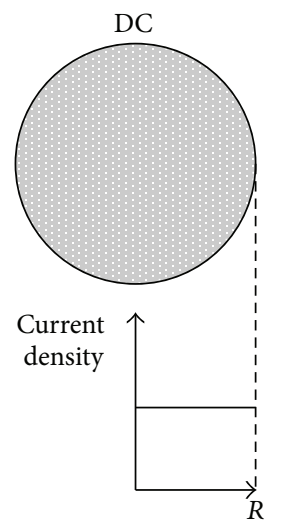

Current is uniformly distributed throughout the conductor

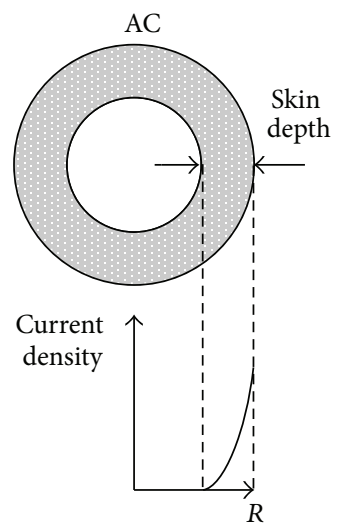

Current is concentrated near the surface and decays exponentially towards the center
FIgure 1: Comparison between DC and AC distribution in a conductor.

system. This is equivalent to adding an extra resistor based on the cable's original resistance. Shorter gap distance will lead to larger eddy current. And larger eddy current leads to larger additional resistor. This phenomenon can also be explained from a microscopic point of view. The magnetic field induced by eddy current exerts Lorentz force upon electrons in the cable and thus "pushes" the current to the top of or "pulls" the current to the bottom of the cable. This also causes reduction of effective cross-sectional area of the cables and increment of resistance. This point will be discussed in more detail with the simulation results in the following section.

2.2. Inductance Analysis. Inductance is related to selfinductance and mutual inductance. Self-inductance consists of external inductance and internal inductance. External inductance derives from magnetic flux outside the cable due to the total current. Here, we call the current in the cable the "total current" with the purpose of distinguishing it from the "portion current," which is bound up with internal inductance. External inductance does not change as frequency varies because it only depends on cable's geometry. Internal inductance is related to flux developed by just a portion, not total, of the current inside the cable [11]. Contrary to external inductance, frequency variation has an impact on internal inductance. Owing to skin effect, higher frequency results in less current near the center of the cable and the internal inductance decreases. In extreme cases, the internal inductance of a cable would vanish if the frequency were high enough. In this case, there is no current in the cable and the total current flows at the surface of the conductor.

Next, we will analyze how the gap distance influences cable inductance. A simple model as shown in Figure 2 is built for explanation. In this model, DC flows through the cable instead of AC since frequency is no longer considered. The cable has a radius of $r_{0}$ and carries a current $I$. The rectangle with dotted line at the bottom of the model represents the aircraft skin and the gap distance is $d$. 


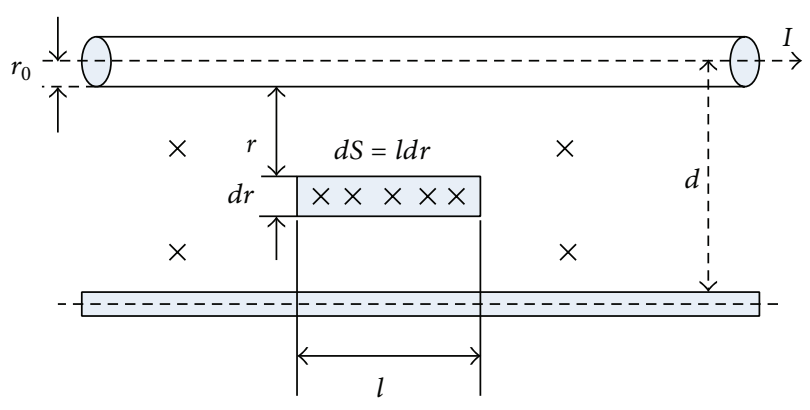

Figure 2: A simplified model showing how the gap distance influences the inductance.

The following expression can be derived according to Ampere's circuital law that the magnetomotive force around a closed path is equal to the total current enclosed by the path:

$$
\oint_{L=2 \pi r} B \cdot d r=\mu_{0} \cdot \sum_{L} I_{i}=\mu_{0} \cdot I
$$

where $B$ is the flux density, $\mu_{0}$ is the permeability of vacuum, and $r$ is the distance between the cable and elementary area whose width is $d r$.

The DC induces steady magnetic field and so there is

$$
B \cdot 2 \pi r=\mu_{0} \cdot I \Longrightarrow B=\frac{\mu_{0} I}{2 \pi r} .
$$

The elementary flux denoted by $d \Phi$ is given by

$$
d \Phi=B \cdot d S=\frac{\mu_{0} I}{2 \pi r} \cdot l \cdot d r
$$

where $l$ is the length of the cable.

Therefore the total flux $\Phi$ is

$$
\Phi=\int d \Phi=\int_{r_{0}}^{d-r_{0}} \frac{\mu_{0} I}{2 \pi r} \cdot l d r=\frac{\mu_{0} I l}{2 \pi} \ln \left(\frac{d-r_{0}}{r_{0}}\right) .
$$

Then the self-inductance of the cable $L$ is calculated by

$$
L=\frac{\Phi}{I}=\frac{\mu_{0} l}{2 \pi} \ln \left(\frac{d-r_{0}}{r_{0}}\right) \approx \frac{\mu_{0} l}{2 \pi} \ln \frac{d}{r_{0}} .
$$

It is noted that the self-inductance of a cable is determined by the gap distance $d$, cable's length $l$, and radius $r_{0}$ [12]. The self-inductance is natural logarithmically increased with increasing gap distance.

Eddy current in aircraft skin also induces magnetic field, a portion of which surrounds the cable and that is the reason why mutual inductance exists. Firstly, higher frequency leads to more remarkable skin effect and larger eddy current which in turn induces stronger magnetic field. So it is almost impossible to verify the impact of frequency on mutual inductance. Secondly, flux generated by eddy current surrounding the cable decreases as gap distance increases. Larger gap distance leads to smaller eddy current and weaker magnetic field. So it is easy to conclude that mutual inductance decreases as the gap distance gets larger. The cable current density is

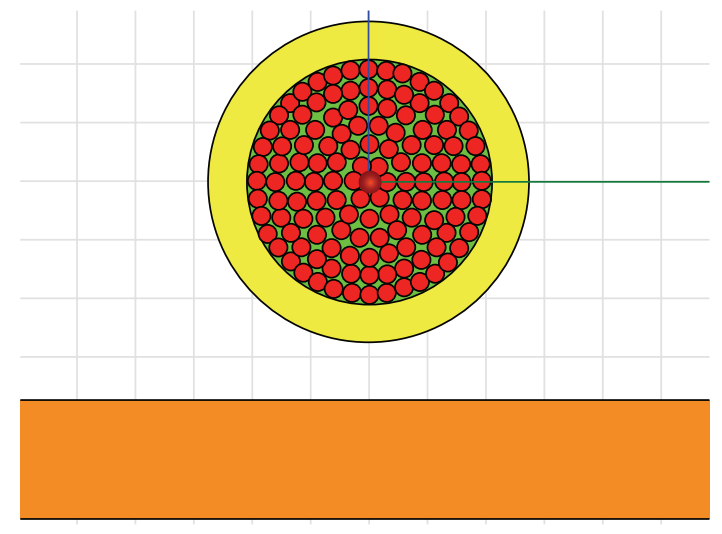

FIgURE 3: An aircraft cable simulation model built in Maxwell 2D.

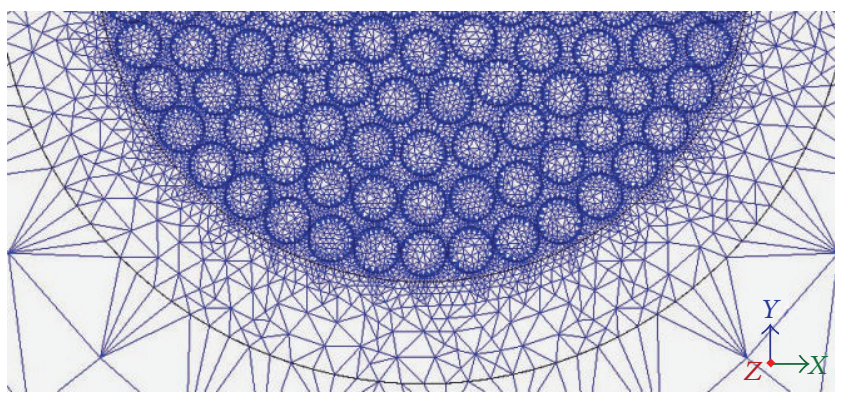

FIGURE 4: Finite element mesh dissection of the simulation model.

ten times larger than the eddy current density in aircraft skin so the self-inductance dominates the total inductance. Above all, a cable's inductance gets larger as the gap distance increases. Due to the complex electromagnetic environment, it is difficult or even impossible to calculate quantitatively. It is better to study it by means of simulation if more precise results are expected.

\section{Simulation Model of Aircraft Cable}

In this paper, the cable model (as seen in Figure 3) is built using the electromagnetic field simulation software-Maxwell 2D, which uses the accurate finite element analysis (FEA) to solve electromagnetic problems [13]. The yellow circular ring represents insulated layer. The red circles denote cores. The green part depicts air gap among the cores. The orange rectangle represents aircraft skin (the aircraft skin is not completely shown because it is too large compared with the cable). Figure 3 shows the condition when the cable clings to the aircraft skin. Since it is impossible to make the aircraft cable cling to the aircraft skin completely in the laboratory, a gap with a length of $2 \mathrm{~mm}$ on average is inserted between the cable and the aircraft skin for the purpose of comparing the simulation results and experimental results, both of which will be illustrated below. Voltage frequency and gap distance can be changed in software settings. Figure 4 shows the mesh dissection of the simulation model partly because the grids are too dense. 

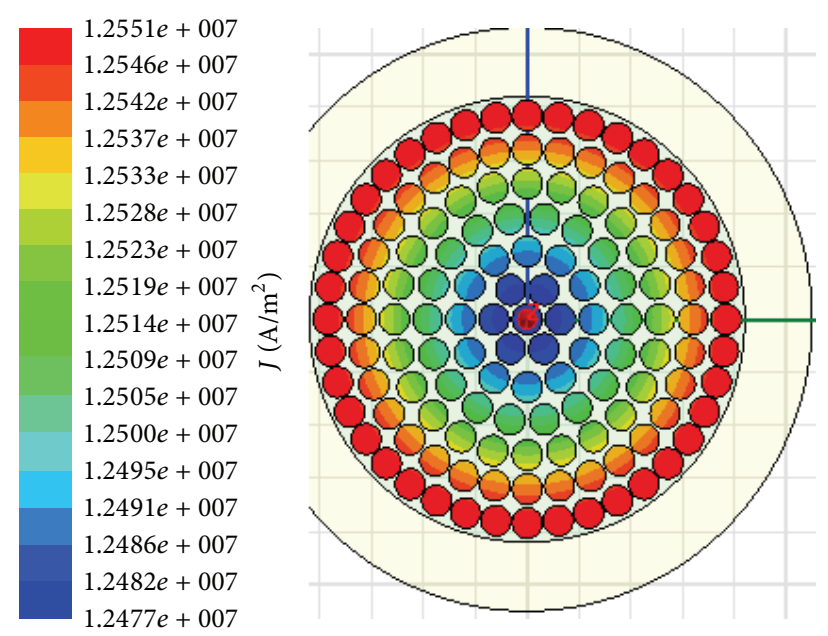

FIgure 5: Current density distribution of the cable at $400 \mathrm{~Hz}$ and gap distance of $110 \mathrm{~mm}$.

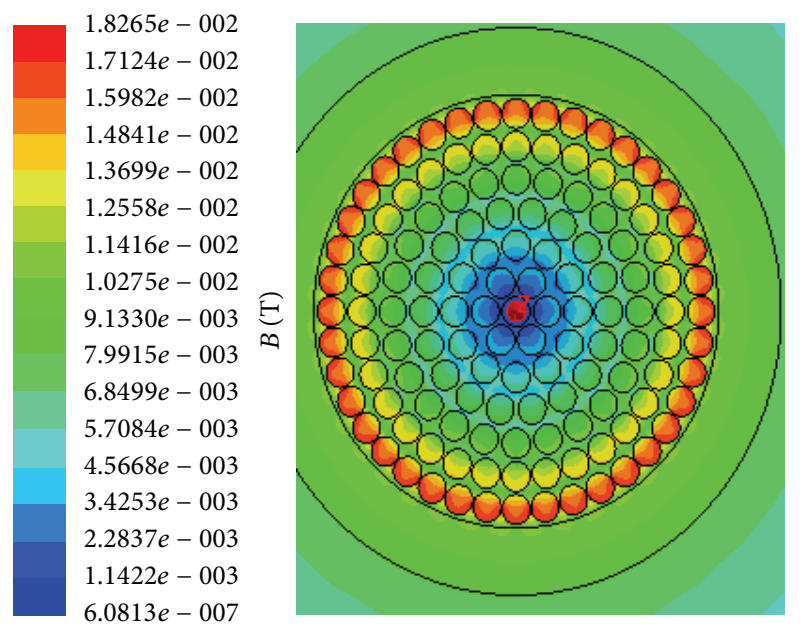

FIGURE 6: Flux density distribution of the cable at $400 \mathrm{~Hz}$ and gap distance of $110 \mathrm{~mm}$.

\section{Analysis of Simulation Results}

4.1. Analysis of Electromagnetic Field Graphs. Since the voltage frequency in aircraft power system is rather low and the frequency range is relatively narrow (from $360 \mathrm{~Hz}$ to $800 \mathrm{~Hz}$ ), the differences are so subtle that the graphs are almost the same at each frequency point intuitively when the gap distance is fixed. So this part concentrates on current density distribution and magnetic flux density distribution graphs at different gap distances and the voltage frequency is fixed at $400 \mathrm{~Hz}$. Figures 5 and 6 show the current density distribution and magnetic flux density distribution when the gap distance is $110 \mathrm{~mm}$.

It can be seen from Figure 5 that the current distribution is very similar to the situation when skin effect occurs. The current density increases from the center to the surface of the cable radially. The reason why the difference in current
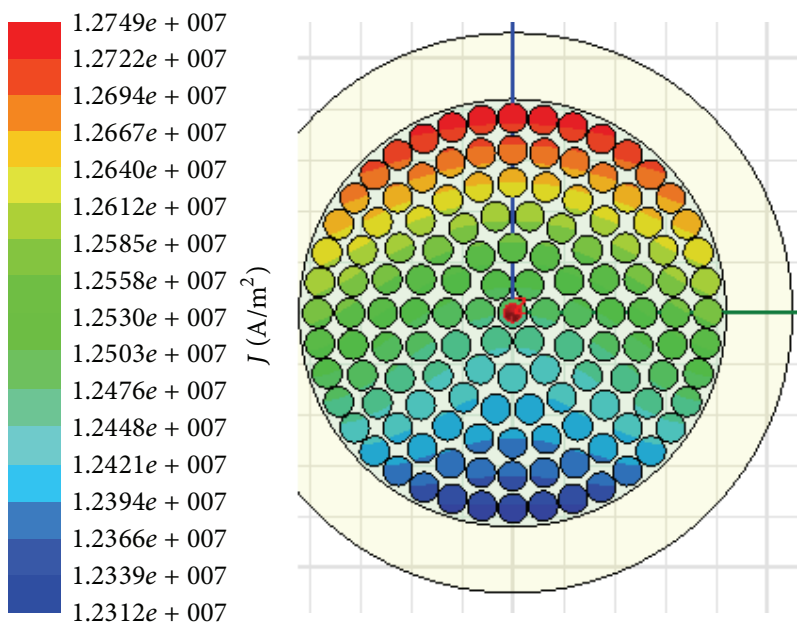

Figure 7: Current density distribution at $400 \mathrm{~Hz}$ and gap distance of $r_{0}$.

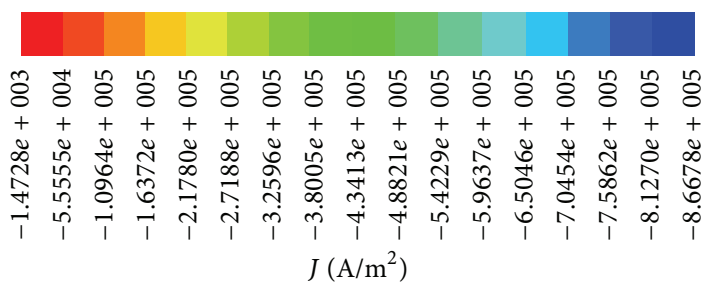

FIGURE 8: Eddy current density distribution in the aircraft skin at $400 \mathrm{~Hz}$ and gap distance of $r_{0}$.

density is not significant is that $400 \mathrm{~Hz}$ is rather low compared with radio frequency which is always higher than $1 \mathrm{MHz}$.

Ampere's circuital law can be used to analyze Figure 6. The magnetic field is weakest at the center of the cable where it contains least current and is strongest at the surface where it surrounds the total current. Beyond the surface, the flux density decreases as the integration path gets longer, while the current that the path encloses remains the same (the total current).

Figure 7 shows the current distribution when the cable clings to the aircraft skin. The eddy current distribution in the aircraft skin, as seen in Figure 8, is also displayed.

Owing to the eddy current in the aircraft skin, Figure 7 differs from Figure 5 obviously. The current density is largest at the top of the cable and decreases vertically to the bottom of the cable. This phenomenon is not obvious when the gap distance is $110 \mathrm{~mm}$, as depicted in Figure 5. The reason is that $110 \mathrm{~mm}$ is much larger than the cable's radius $r_{0}$, which is less than $3 \mathrm{~mm}$, and the eddy current in the aircraft skin is so low that the eddy effect is negligible. In fact, the current distribution is always influenced by the aircraft skin more or less.

Minus current density in aircraft skin, as shown in Figure 8 , means the eddy current flows in the opposite direction compared with the cable current. It is easy to understand that 


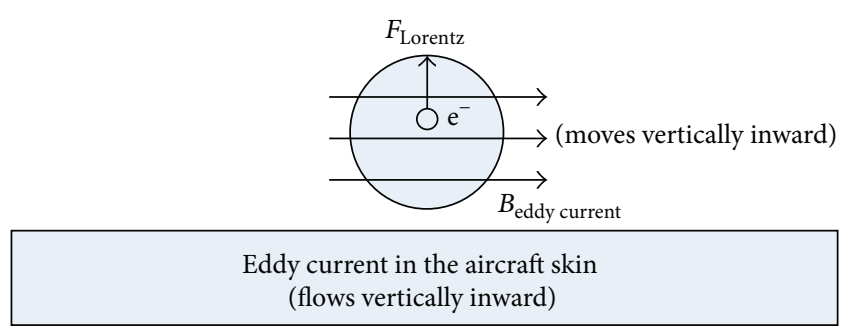

FIGURE 9: The effect of aircraft skin on the cable current distribution.
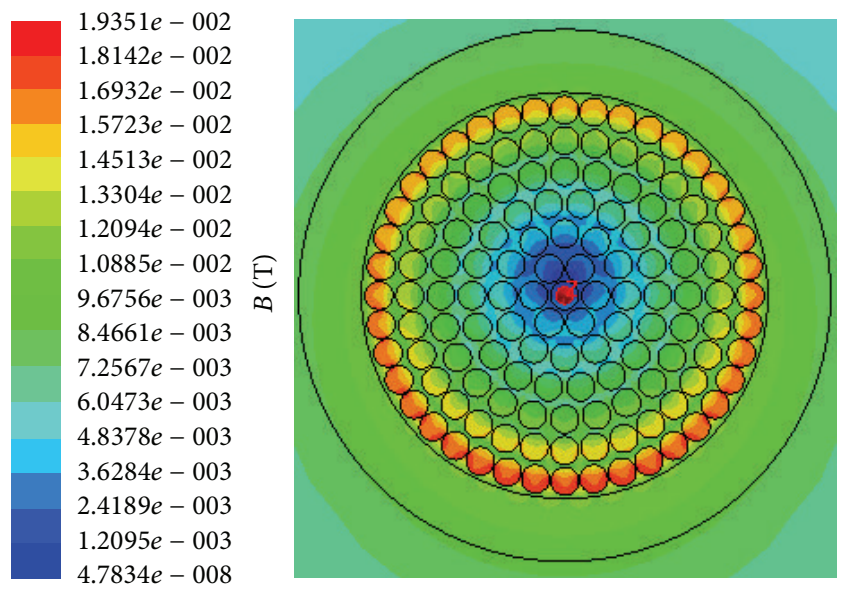

FIgURE 10: Flux density distribution at $400 \mathrm{~Hz}$ and gap distance of $r_{0}$.

the closer the cable to the aircraft skin, the larger the eddy current density.

Figure 9 explains how the aircraft skin influences the distribution of the cable current. According to the software settings, the cable current is positive, namely, vertical to the paper outward, and that means the current carriers-electrons move vertical to the paper inward. Figure 8 implies that the eddy current is negative inducing magnetic field which exerts straight up force on the electrons according to Lorentz force law. As a result, the current flows as if it is "pushed" to the top of the cable. Larger gap distance leads to weaker magnetic field and less Lorentz force. And the cable current distribution will be more likely the same as Figure 5. Different current density means different effective cross-sectional area of the cable. Shorter gap distance results in less effective crosssectional area and larger resistance.

The flux density distribution under this condition is shown in Figure 10. Eddy current also makes the flux density distributed unsymmetrically compared with Figure 6 . The blue part no longer locates at the exact center of the cable as if it is also "pushed" by the aircraft skin. Special attention should be paid that the maximum flux density locates at the bottom of the cable where the current density is the lowest. As shown in Figure 10, the color is darker at the bottom of the cable than that at the top of it. From Figures 7 and 8 we can see that the difference between the maximum and minimum current density in the cable is $0.0437 \times 10^{7} \mathrm{~A} / \mathrm{m}^{2}$ which is only half of the largest eddy current density, as high as $8.6678 \times 10^{5} \mathrm{~A} / \mathrm{m}^{2}$,

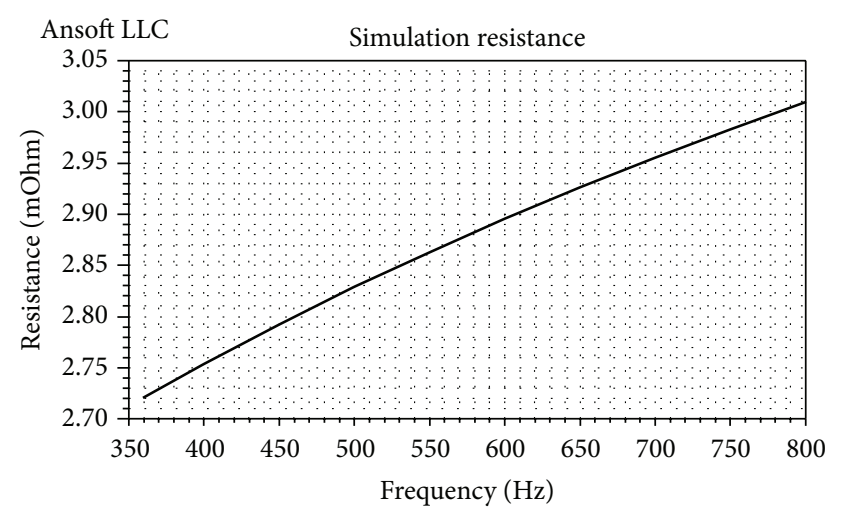

FIGURE 11: Resistance versus frequency curve at gap distance of $r_{0}$ $(\mathrm{mOhm} / \mathrm{m})$.

and the eddy effect should not be neglected. Both the cable current and the eddy current generate rightward magnetic field at the bottom of the cable and that is why minimum current density corresponds to maximum flux density.

There are two points that need to be further explained. Firstly, the current excitation's initial phase is 0 and all the simulation graphs are derived at this moment, which means different current and flux density distribution will be obtained if other phases are chosen when viewing the simulation results. Secondly, as illustrated before, the graphs are almost the same at each frequency point intuitively when the gap distance is fixed. For example, when the cable clings to the aircraft skin and the frequency is $800 \mathrm{~Hz}$, another current density distribution graph can be obtained. This graph is very similar to Figure 7 which is obtained when the cable clings to the aircraft skin and the frequency is $400 \mathrm{~Hz}$. The only difference between the two graphs is that the same color in the legends represents different current density. However, these two points above will not affect the results of the research. For example, no matter what direction the eddy current is, namely, whether the aircraft skin "pushes" or "pulls" the cable current, effective cross-sectional area of the cable decreases and resistance increases. Current distribution affects resistance and flux density influences inductance. Cable impedance is a result of comprehensive effect of all these factors mentioned above.

4.2. Analysis of Simulation Data. The simulation results can be viewed in a simpler way. When the cable clings to the aircraft skin, resistance increases and inductance decreases with higher frequency, as shown in Figures 11 and 12. The resistance and inductance data at different gap distances can be obtained by changing the simulation model. In fact, the change trends of resistance and inductance as frequency increases at other gap distances are the same as the condition when the cable clings to the aircraft skin. All the simulation data under different conditions (different frequencies and different gap distances) is shown in Figures 13 and 14. The resistance and inductance of 1000 meters of the cable are derived by simply multiplying 1000 to the data obtained from simulation which calculates one meter of the model using FEA by default. 


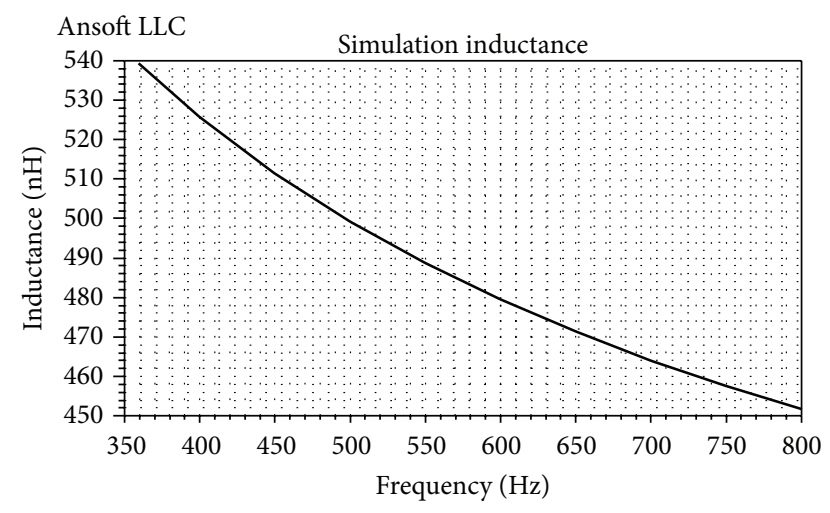

FIGURE 12: Inductance versus frequency curve at gap distance of $r_{0}$ $(\mathrm{nH} / \mathrm{m})$.

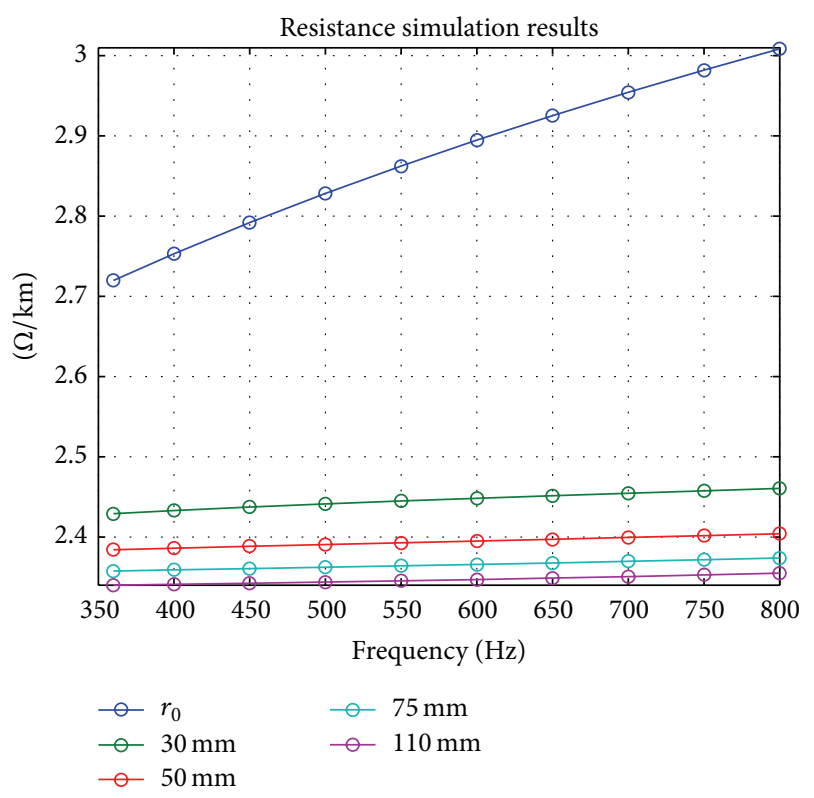

FIGURE 13: Resistance simulation data $(\Omega / \mathrm{km})$.

Same conclusions can be drawn from Figures 13 and 14. The resistance of aircraft cables increases as a result of voltage frequency increases and gap distance decreases. The inductance of aircraft cables increases as a result of voltage frequency decreases and gap distance increases.

\section{Impedance Characteristics of Bunched Wires}

In order to make full use of the limited space inside the cabin and to install the electric wires easily, wires on the aircraft are generally laid bunched together. There is no doubt that the impedance of wires transmitting electric power will change when the wires laid pattern changes from single and separated into multiple and bunched. To ensure the safe operation of the wire and to guarantee that the electrical equipment will not work improperly as the voltage drop on the wire is too

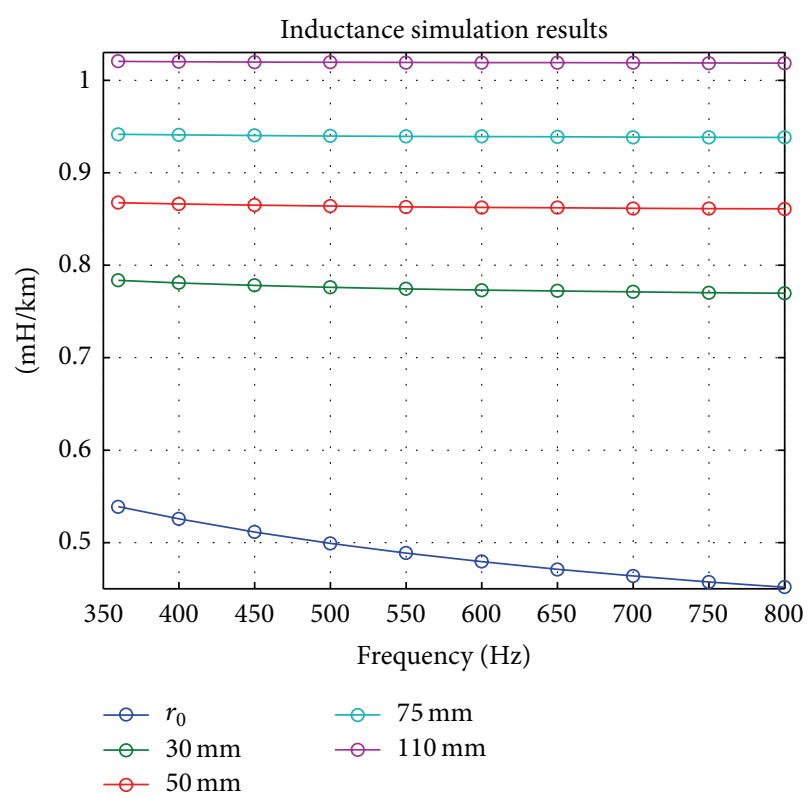

FIGURE 14: Inductance simulation data $(\mathrm{mH} / \mathrm{km})$.

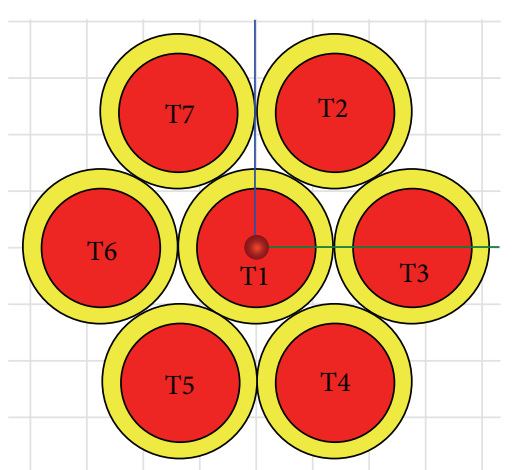

FIGURE 15: The basic model of bunched wires.

large, it is necessary to study the impedance characteristics of the bunched laid wires.

The basic model of bunched laid wires is shown in Figure 15, and the seven wires are named T1 to T7 separately. The factor influencing the wire's impedance under test is the current amplitude and phase. Different wire diameter means the amplitude of the current flowing through the wire is different. Besides, when multiple wires are bunched together, the core wire $\mathrm{T} 1$ of the bunch is affected most severely by the neighborhood wires mutual inductance and proximity effect, and its impedance change is larger compared to being laid alone. Therefore, this paper studies how the core wire's impedance of bunched laid wires changes when the external wires diameter and phase of current are different.

There are five main laid patterns of the bunched wires for one main-generator (setting the frequency at $400 \mathrm{~Hz}$ ).

The first type: the seven wires diameters are equal to each other, and the current amplitude and phase are also the same whose amplitudes are all $10 \mathrm{~V}$, which is shown in Figure 15. 


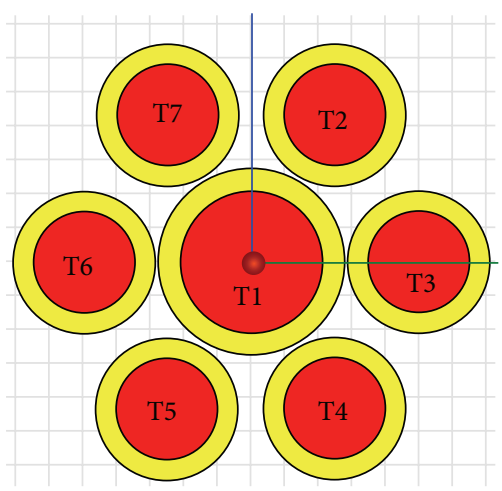

FIGURE 16: The second laid pattern.

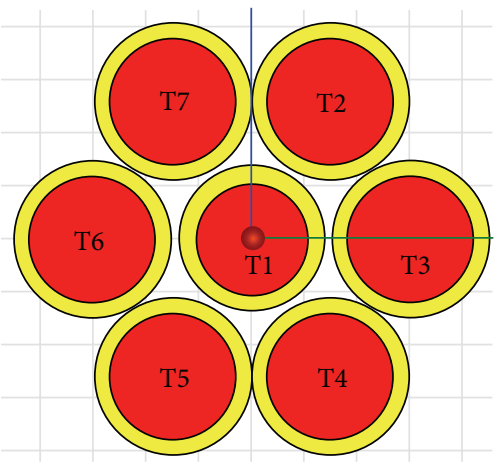

Figure 17: The third laid pattern.

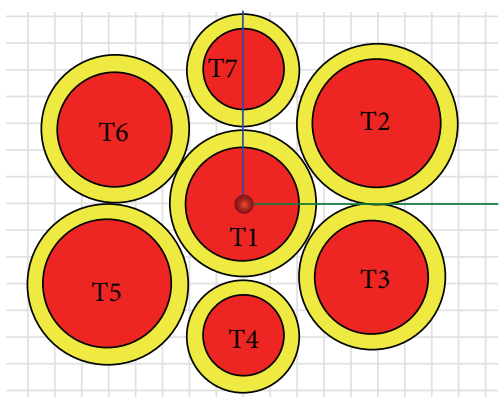

Figure 18: The fourth laid pattern.

The second type: the diameter from T2 to T7 is smaller than $\mathrm{T} 1$, and the current flowing through them is $5 \mathrm{~A}$, whereas the current of $\mathrm{T} 1$ is $10 \mathrm{~A}$, and every wire's initial phase is 0 degree, which is shown in Figure 16.

The third type: the diameter from T2 to T7 is greater than $\mathrm{T} 1$, and the current flowing through them is $20 \mathrm{~A}$, whereas the current of T1 is $10 \mathrm{~A}$, and every wire's initial phase is 0 degree, which is shown in Figure 17.

The fourth type: T3 and T6 have the same diameter as T1, and the three wires' current is $10 \mathrm{~A}$, whereas T2 and T5 have greater diameter than T1, whose current is $20 \mathrm{~A}$, and the diameter of T4 and T7 is smaller than T1 with $5 \mathrm{~A}$ current flowing through them, shown in Figure 18. And every wire's initial phase is 0 degree.

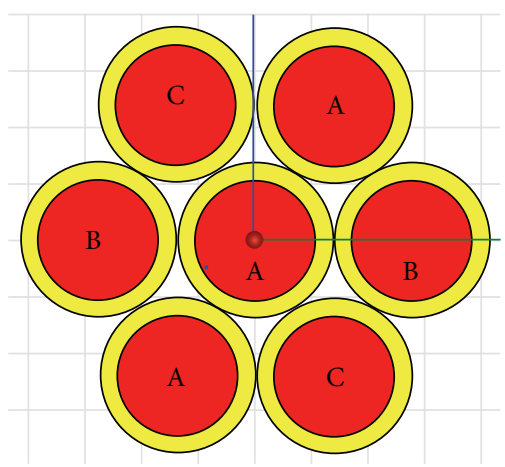

FIGURE 19: The fifth laid pattern.

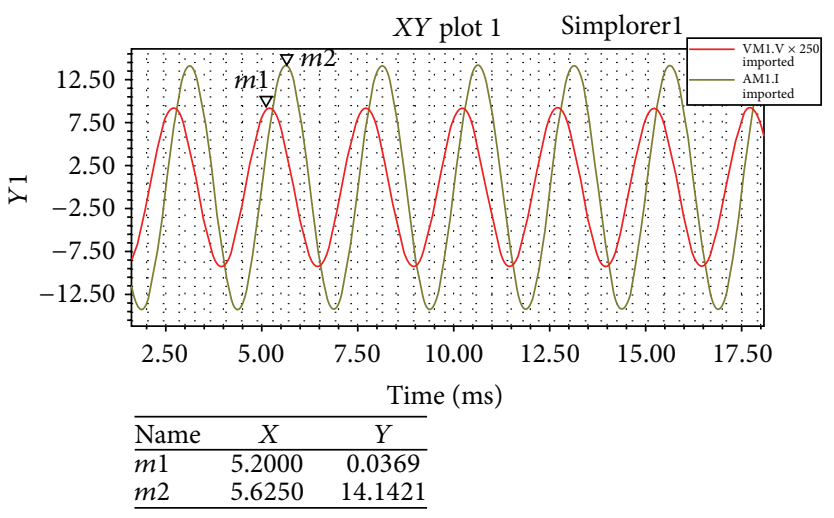

\begin{tabular}{lcccc}
\hline Name & $\operatorname{Delta}(X)$ & $\operatorname{Delta}(Y)$ & $\operatorname{Slope}(Y)$ & $\operatorname{InvSlope}(Y)$ \\
\hline$d(m 1, m 2)$ & 0.4250 & 14.1053 & 33.1888 & 0.0301 \\
\hline
\end{tabular}

FIGURE 20: Voltage and current waveforms obtained by cosimulation.

The fifth type: the seven wires diameters are equal to each other, and the current flowing through them is $10 \mathrm{~V}$. To maximize the symmetry, A phase electric is connected to $\mathrm{T} 1, \mathrm{~T} 2$, and $\mathrm{T} 5, \mathrm{~B}$ phase electric is connected to T3 and T6, and $\mathrm{C}$ phase electric is connected to T4 and T7, as shown in Figure 19.

Figure 20 shows the voltage and current waveforms of the studied wire obtained by cosimulation.

Comparing the impedance data of the first three types, it can be found that the core wire's impedance value increases with the external wires current amplitude increasing. This is because the proximity effect and the mutual induction between the core wire and the external wires increase when the external wires current amplitude increases. The proximity effect makes the core wire resistance increase, and the mutual induction makes the cores wire reactance increase, so the total impedance value of the core wire increases.

As for the fourth type, even though the average current on each wire is equal to the first one, the wire diameter and the current flowing through the wires is asymmetric, making the voltage drop on wire T1 largest, so the impedance value of $\mathrm{T} 1$ is largest. 

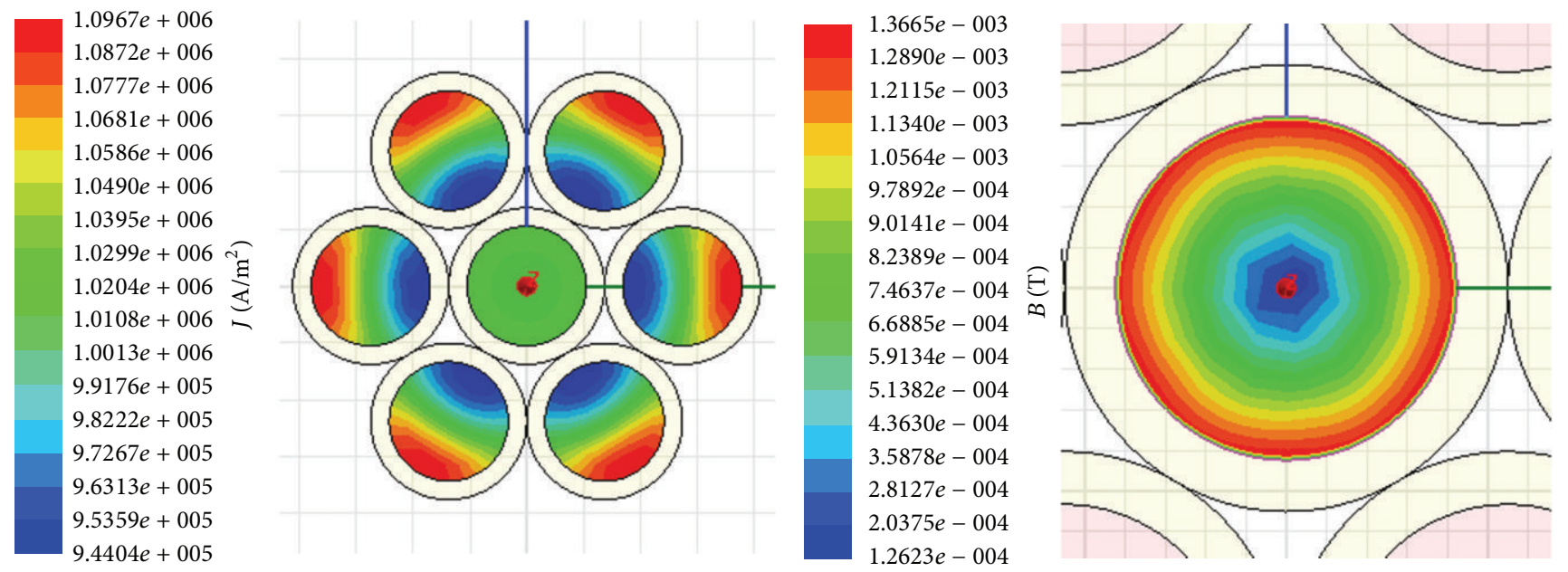

FIGURE 21: The current density and the magnetic field intensity distribution on wire T1 under the first laid pattern.
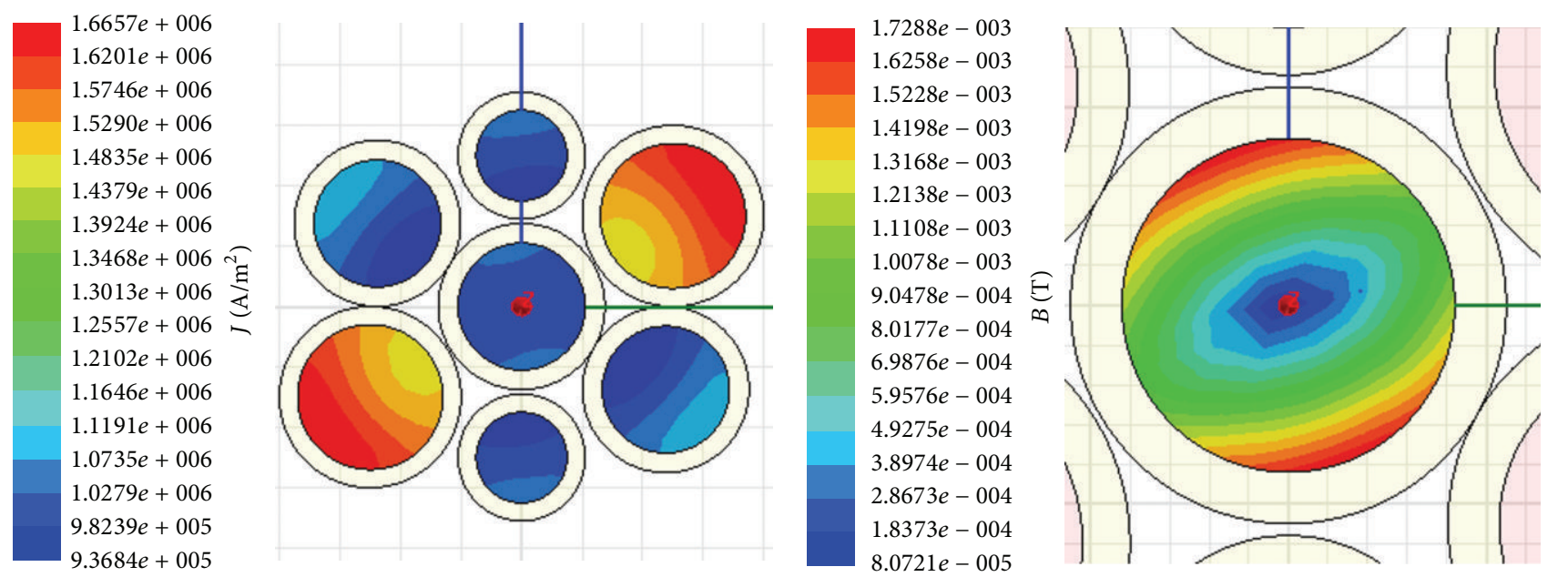

FIgURE 22: The current density and the magnetic field intensity distribution on wire T1 under the fourth laid pattern.

Next, the current density and the magnetic field intensity distribution on wire $\mathrm{T} 1$ under the first and the fourth laid patterns are studied.

As can be seen from Figure 21, the current density distribution on wire $\mathrm{T} 1$ is uniform when the current within the external wires is the same as the current of the core wire, and this is because the proximity effects from external wires cancel each other, whereas external wires present that the current density is small near the side of the core wire and large away from the side of the core wire. In Figure 22, the current density distribution on wire T1 appears not uniformly compared with that in Figure 21, and this is because the current in $\mathrm{T} 2$ and $\mathrm{T} 5$ is larger than the current in $\mathrm{T} 1$, whereas the current in T4 and T7 is smaller than that in T1; hence the proximity effect is significant where $\mathrm{T} 1$ is close to $\mathrm{T} 2$ and T5, making the current density become smaller, and the proximity effect is weak where $\mathrm{T} 1$ is close to $\mathrm{T} 4$ and $\mathrm{T} 7$, which makes the current density relatively large, and the equivalent cross-sectional area which the current in $\mathrm{T} 1$ flows through decreases, so the resistance of wire $\mathrm{Tl}$ increases.
The magnetic field intensity distribution on wire $\mathrm{T} 1$ is the same as the corresponding current density distribution in the first and fourth types separately, but the flux on the cross section of wire $\mathrm{T} 1$ in the fourth type is much larger than that in the first type, so the reactance value of wire $\mathrm{Tl}$ in the fourth type is larger compared with that in the first type.

Comparing the data in the first type with the data in the fifth type in Table 1, it can be seen that the impedance of wire T1 being laid three-phase symmetrically is much smaller than that laid bunched together when wires are flowing through the same phase current, and the impedance of T1 in the fifth type is even smaller than the impedance of $\mathrm{T} 1$ in the second type. From the above analysis of the two wires' impedance matrix in the modeling section, it can be learned that if three-phase symmetric current flows through the external wires, the synthetic voltage drop on wire $\mathrm{Tl}$ will be weakened greatly, making the impedance value of the core wire T1 least.

This finding can be viewed as useful reference for aeronautical engineering. To ensure the safe operation of the wire in bunched laid wires and to reduce voltage drop and 


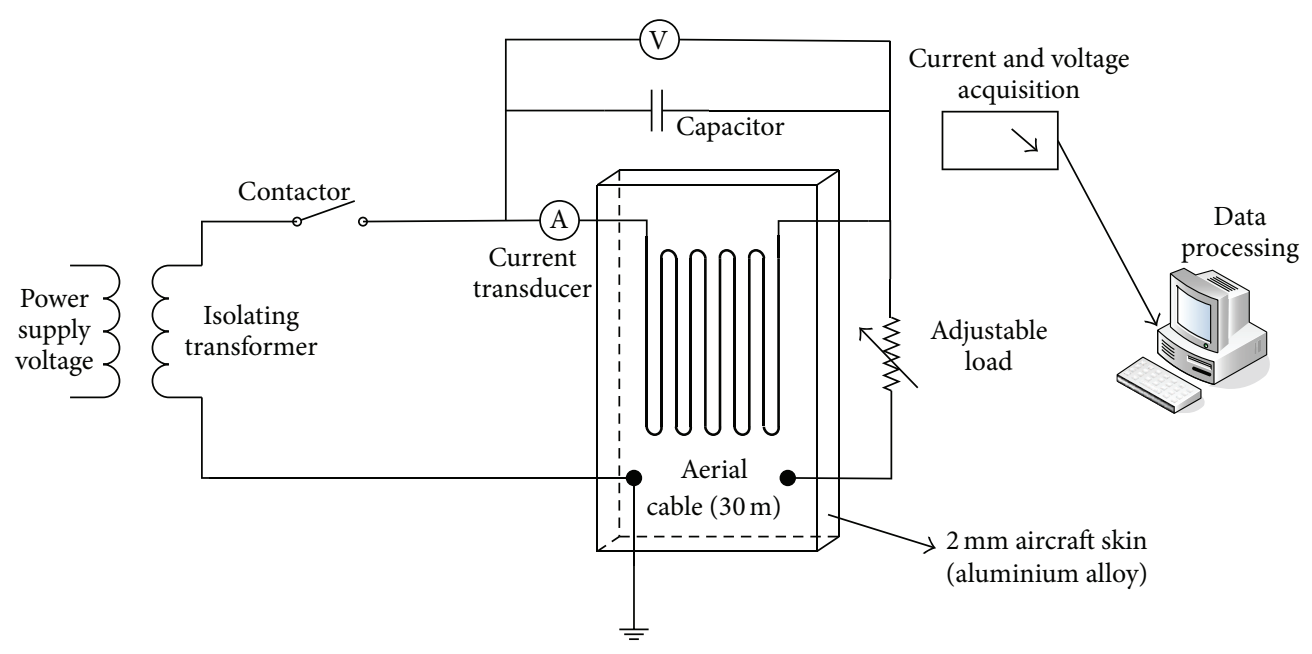

FIGURE 23: Laboratory experiment setup.

TABLE 1: Impedance of the core wire T1.

\begin{tabular}{lccc}
\hline Laid patterns & $Z(\Omega / \mathrm{km})$ & $R(\Omega / \mathrm{km})$ & $X(\Omega / \mathrm{km})$ \\
\hline I & 16.051 & 1.4101 & 15.989 \\
II & 9.341 & 1.2870 & 9.251 \\
III & 29.225 & 1.8350 & 29.167 \\
IV & 52.015 & 4.5695 & 51.813 \\
V & 3.090 & 1.1735 & 2.858 \\
\hline
\end{tabular}

power loss in distribution lines, we should follow these rules: if the external wires can be laid three-phase symmetrically, they cannot be laid bunched together if the external wires flow through the same phase current. When it has to be laid bunched together, the diameter of the external wires should be smaller than that of the core wire to weaken the influence of proximity effect on the core wire in bunched wires. And external wires with different diameter are avoided being bunched laid together.

\section{Comparison between Simulation Results and Experimental Results}

Impedance measurement experiment on aircraft cables was conducted in laboratory by using spectral analysis method $[14,15]$ for $30 \mathrm{~m}$ of the aircraft cable based on which the simulation model is built. The experimental setup is shown in Figure 23.

The current flows through contactor, current transducer, aircraft cables, adjustable load, and aircraft skin and ground successively. A filter capacitor is connected in parallel with the aircraft cable with the purpose of smoothing harmonic waves. Overcurrent can be avoided owing to the adjustable load. Aircraft cables are laid above the aircraft skin with the gap distance ranging from the cable's radius $r_{0}$ to $110 \mathrm{~mm}$. The ammeter and voltmeter imply that the current data and voltage data are both needed, including each amplitude and phase. The data is not acquired using actual ammeter and voltmeter which are too inaccurate. The current is measured

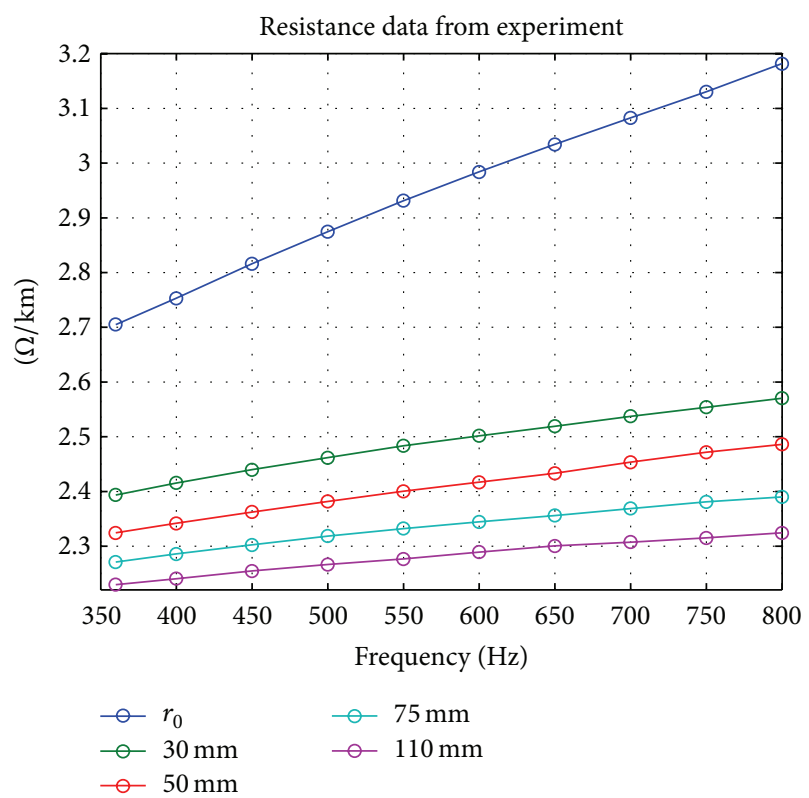

Figure 24: Resistance data from experiment $(\Omega / \mathrm{km})$.

using a current transducer produced by LEM Company and converted into a voltage signal with a precise resistance. Both the converted voltage signal and the voltage across the measured aircraft cable are collected at a sampling rate as high as $200 \mathrm{k} / \mathrm{s}$ using GEN7t high-speed data acquisition equipment, HBM Corporation [16]. Then the data is processed by computer program to calculate the resistance and inductance of the aircraft cable. The results have been converted from room temperature to $20^{\circ} \mathrm{C}$ and are shown in Figures 24 and 25 .

Same conclusion as illustrated in Section 4 can be drawn from the laboratory test data. This finding can be viewed as useful reference for aeronautical engineering. For example, it is better to lay the aircraft cables clinging to the aircraft skin to reduce the cross talk [17], but the resistance is largest under this condition and this means more power loss. Even 


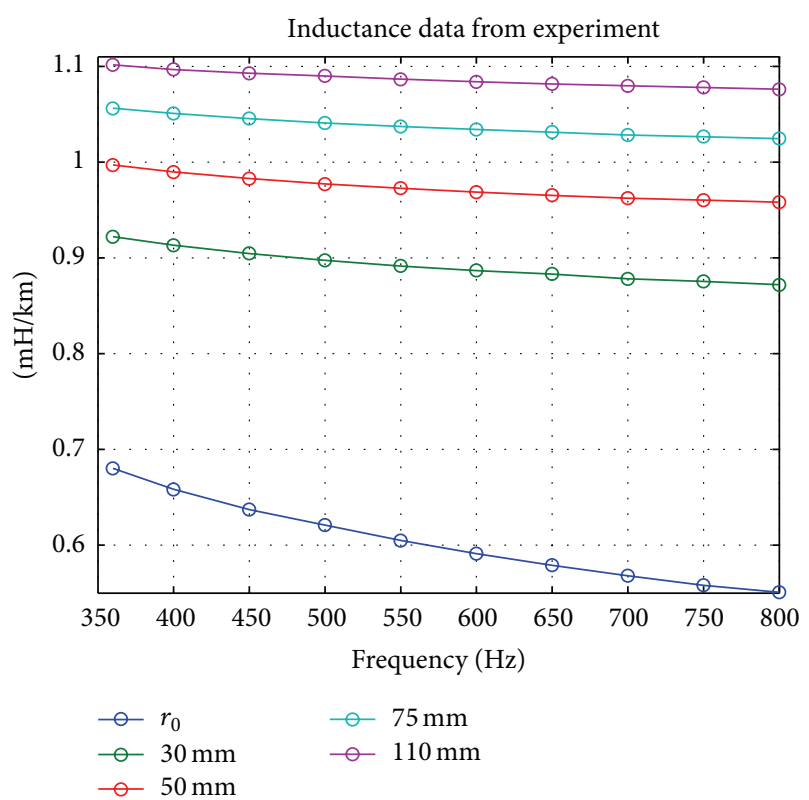

FIGURE 25: Inductance data from experiment ( $\mathrm{mH} / \mathrm{km})$.

if the gap distance is no longer considered, the resistance at $800 \mathrm{~Hz}$ is nearly eighteen percent larger than that at $360 \mathrm{~Hz}$, and it implies more power loss as well. However, shorter gap distance and higher frequency become advantages when it comes to the inductance because the inductance is less under these conditions. As is known to all, inductance of a cable causes phase lag of the current and that is the reason why reactive power exists. Less inductance leads to lower reactive power and the generator could be designed smaller and lighter. Compromise has to be reached when laying aircraft cables on aircraft.

It should be noticed that although the trend of the simulation data shows good consistency with the laboratory test data, the absolute value of the inductance differs a lot. For instance, the error is as large as $20 \%$ when the cable clings to the aircraft skin. All these are due to reasons as follows:

(1) Due to business secret protection and other reasons, it is impossible to get accurate values of the sizes and materials of the cables and aircraft skin, which are extremely important in modeling process. Relative permittivity, relative permeability, bulk conductivity, dielectric loss tangent, and magnetic loss tangent are all essential parameters. The model used in this paper is constructed based on author's experience and data searched from the Internet.

(2) The simulation model is not accurate enough. For example, parallel nickel-clad copper cores are used instead of stranded conductors for convenience of modeling. And also actual aircraft cables consist of armors, sheaths, gaskets, and other components except for conductors and insulations which make up the simulation model roughly $[17,18]$.
(3) The model simulates the resistance and inductance of cables that are arranged straightly but it is hard to realize in an area-limited laboratory. Thus the simulation data cannot take the proximity effect and other electromagnetic interferences into account.

\section{Data Analysis}

In fact, impedance measurement experiments are carried out on six types of cables which are denoted by A, B, C, D, E, and $\mathrm{F}$, respectively, and $r_{\mathrm{A}}>r_{\mathrm{B}}>r_{\mathrm{C}}>r_{\mathrm{D}}>r_{\mathrm{E}}>r_{\mathrm{F}}(r$ is the radius of the cable). The simulation model built in Section 3 is based on B. In this section, four parameters of interest are analyzed: resistance $R$, inductance $L$, reactance $X$, and impedance $Z$.

For each type of cables, as illustrated before, $R$ increases as a result of voltage frequency increases and gap distance decreases. And the larger $r$, the smaller the absolute value of $R$ when voltage frequency and gap distance are the same. $R$ increases more rapidly when the cable clings to the aircraft skin compared with other gap distances.

For each type of cables, as illustrated before, $L$ increases as a result of voltage frequency decreases and gap distance increases. And the larger $r$, the smaller the absolute value of $L$ when voltage frequency and gap distance are the same. $L$ decreases more rapidly when the cable clings to the aircraft skin compared with other gap distances.

From the equation $X=\omega L=2 \pi f L$ we know that $X$ is determined by both voltage frequency $f$ and $L$. Although inductance decreases with frequency increasing, $X$ still increases with frequency increasing according to the calculation results. This means increasing frequency has greater effect on $X$ than decreasing $L$. And the larger $r$, the smaller the absolute value of $X$ when voltage frequency and gap distance are the same.

From the equation $Z=\sqrt{R^{2}+X^{2}}$ we know that $Z$ is determined by both $R$ and $X$. When the voltage frequency and gap distance are the same, both of $R$ and $X$ become smaller as $r$ increases, so $Z$ becomes smaller as $r$ increases. And for a certain type of cable, both $R$ and $X$ get larger as frequency increases, so $Z$ becomes larger as frequency increases. However, the influence of gap distance on $Z$ is not as simple because $R$ and $X$ follow different change trends as gap distance increases. For cables with smaller $r$ like $D, E$, and $\mathrm{F}, R$ is much larger than $X(R \gg X)$ and $R$ dominates $X$ so how the gap distance affects $Z$ depends on how the gap distance affects $R$, while for cables with larger $r$ like $\mathrm{A}, \mathrm{B}$, and $C, X$ is not much less than $R$ or even larger than that so how the gap distance affects $Z$ depends on how the gap distance affects both $R$ and $X$. For $\mathrm{A}$ and $\mathrm{B}, Z$ increases as the gap distance increases. For D, E, and F, $Z$ decreases as the gap distance increases. For $C, Z$ decreases as the gap distance increases in low-frequency range and $Z$ increases as the gap distance increases in high-frequency range.

\section{Conclusions}

This finding of this paper can be viewed as useful reference for aeronautical engineering. To reduce voltage decrease and 
power loss in distribution lines in the process of impedance calculation for aircraft electrical power grid, cables with large radius should be placed near the aircraft skin while those with smaller radius should be placed as far away from the aircraft skin as possible.

The above analysis only takes grid impedance into account and a compromise formula may have to be adopted under comprehensive considerations. For example, it is better to lay aircraft cables clinging to aircraft skin to reduce the cross talk, but the resistance is largest under this condition and this means more power loss. Even if the gap distance is no longer considered, the resistance at $800 \mathrm{~Hz}$ is larger than that at $360 \mathrm{~Hz}$, and it implies more power loss as well. However, shorter gap distance and higher frequency become advantages when it comes to the inductance because the inductance is less under these conditions. Less inductance leads to lower reactive power and the generator could be designed smaller and lighter. Compromise has to be reached when laying cables on aircrafts.

\section{Competing Interests}

The authors declare that they have no competing interests.

\section{Acknowledgments}

This work is supported by State Key Laboratory of Electrical Insulation and Power Equipment (Grant no. EIPE14203), the Shaanxi Key Laboratory of Small and Special Electrical Machines and Drive Technology (Grant no. 2013SSJ1001), State Key Laboratory of Alternate Electrical Power System with Renewable Energy Sources (Grant no. LAPS15018), the Fundamental Research Funds for the Central Universities (Grant no. 3102015ZY052), and the National Nature Science Foundation of China (Grant no. 51407144).

\section{References}

[1] G. H. Cheng, "Current situation and development of electrical power system on large civil aircrafts," Civil Aircraft Design and Research, vol. 4, pp. 2-4, 2008.

[2] HB5795-82 Current-Carrying Capacity of Aircraft Cables, Third Ministry of Machinery Industry of People's Republic of China, Beijing, China, 1982.

[3] P. Priyanka, "Calculation of total inductance of a straight conductor of finite length," Physics Education, pp. 193-199, 2009.

[4] M. Vitelli, "Calculation of per-unit-length resistance and internal inductance in 2-D skin-effect current driven problems," IEEE Transactions on Electromagnetic Compatibility, vol. 44, no. 4, pp. 529-538, 2002.

[5] X. Z. Wu, "Resistance calculation of AC transmission lines," Electric Wire and Cable, vol. 5, pp. 2-6, 1998.

[6] B. Z. Lu and Z. C. Liu, "Experimental study of skin effect," Physics Examination and Testing, vol. 4, pp. 16-17, 2004.

[7] E. J. Woods, "High-frequency characterization of power wiring for modeling," in Proceedings of the IEEE International Electric Machines and Drives Conference (IEMDC '99), pp. 722-724, IEEE, Seattle, Wash, USA, May 1999.
[8] W. Li, W. Liu, S. Liu, R. Ji, and X. Zhang, "Impedance characteristics study of three-phase aircraft power wires," Measurement, vol. 78, pp. 235-244, 2016.

[9] R. W. Erickson and D. Maksimovic, Fundamentals of Power Electronics, Kluwer Academic Publishers, New York, NY, USA, 2nd edition, 2001.

[10] W. Li, A. Monti, and F. Ponci, "Fault detection and classification in medium voltage dc shipboard power systems with wavelets and artificial neural networks," IEEE Transactions on Instrumentation and Measurement, vol. 63, no. 11, pp. 2651-2665, 2014.

[11] X. D. Liang, A. C. Qiu, and C. X. Sun, China Electrical Engineering Cannon, China Electric Power Press, Beijing, China, 2009.

[12] Inductance of a Straight Conductor, http://nptel.iitm.ac.in/ courses/Webcourse-contents/IIT-KANPUR/power-system/chapter_1/1_4.html.

[13] B. Zhao and H. L. Zhang, Engineering Application of Ansoft12 in Electromagnetic Field, China Water Power Press, Beijing, China, 2011.

[14] F. Corrêa Alegria and A. Cruz Serra, "Comparison between two digital methods for active power measurement," in Proceedings of the IEEE International Conference on Industrial Technology (ICIT '10), pp. 211-216, IEEE, Vi a del Mar, Chile, March 2010.

[15] T. Y. Liu, Study on impedance measurement methods of aircraft cables [Ph.D. dissertation], Northwestern Polytechnical University (NWPU), Xi'an, China, 2011.

[16] W. Li, M. Ferdowsi, M. Stevic, A. Monti, and F. Ponci, "Cosimulation for smart grid communications," IEEE Transactions on Industrial Informatics, vol. 10, no. 4, pp. 2374-2384, 2014.

[17] L. G. Ruan, L. Cai, Q. Xiao, and L. Wang, "Analysis of crosstalk among aircraft wires," Civil Aircraft Design and Research, vol. 4, pp. 16-19, 2008.

[18] J. B. Li, C. Lin, and J. H. Li, Manual on Electrical Cables Selection, Chemical Industry Press, Beijing, China, 2011. 


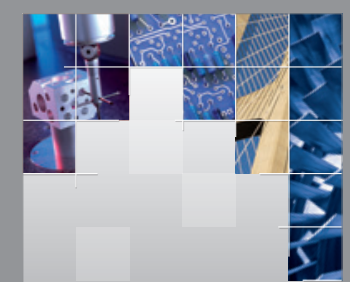

\section{Enfincering}
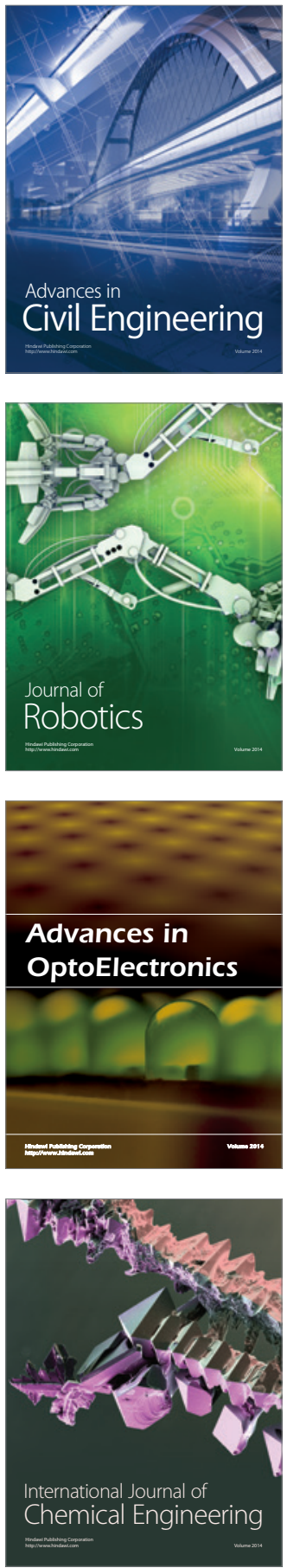

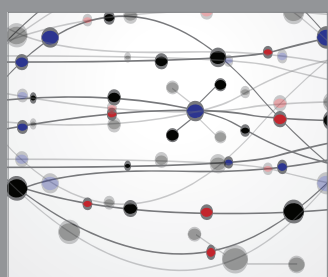

The Scientific World Journal

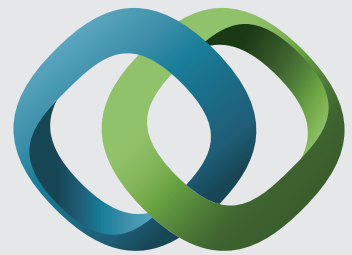

\section{Hindawi}

Submit your manuscripts at

http://www.hindawi.com
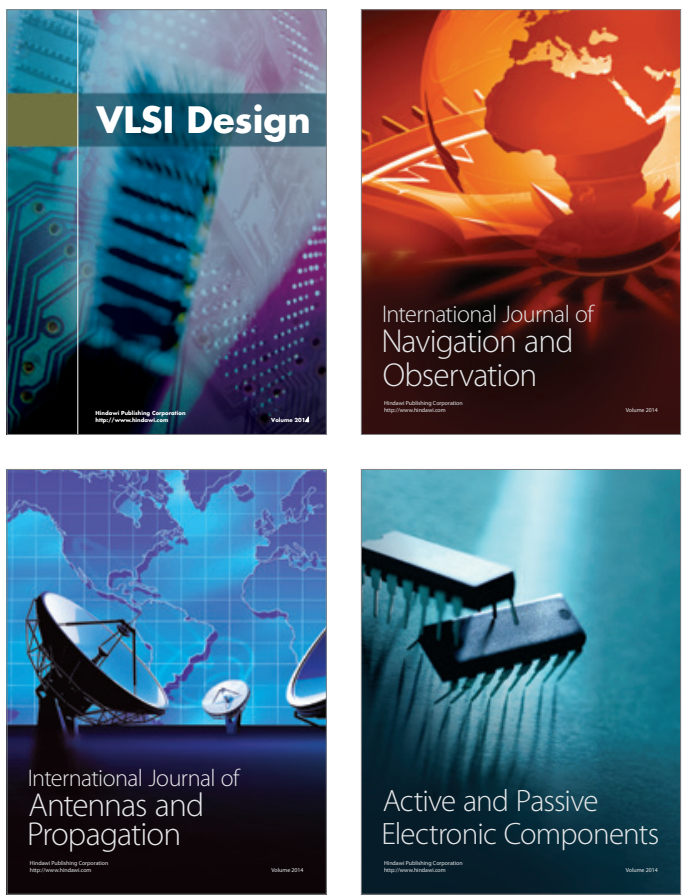
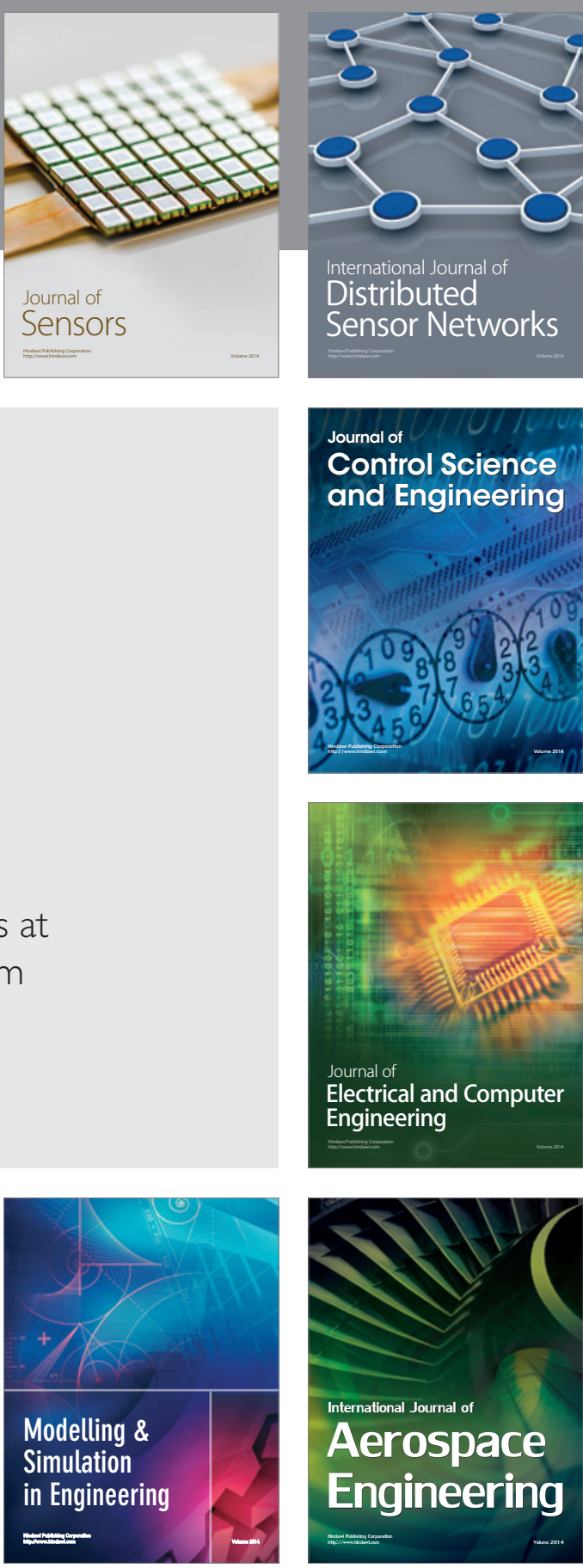

International Journal of

Distributed

Sensor Networks

Journal of

Control Science

and Engineering
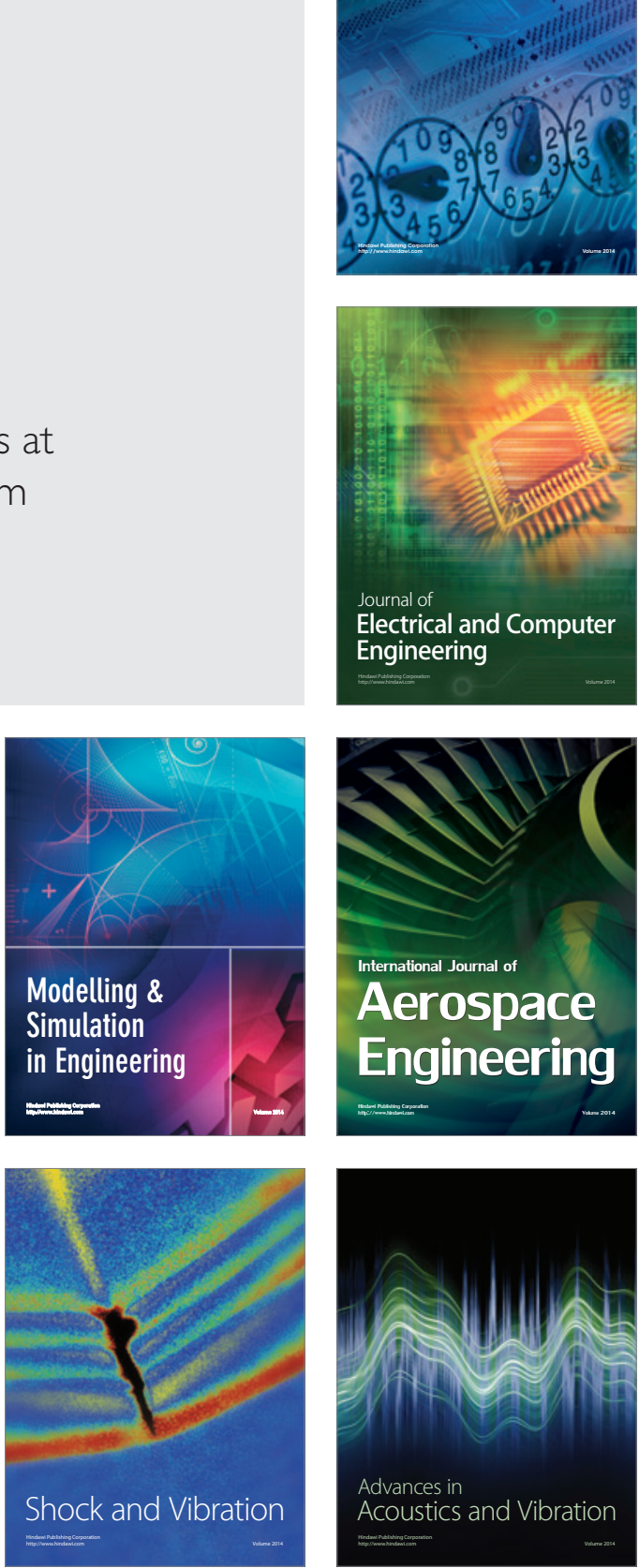